\title{
HUBUNGAN ANTARA PERSEPSI PASIEN TENTANG KUALITAS DAN KEMAUAN MEMBAYAR PELAYANAN KESEHATAN GIGI DI MMC UMS
}

\author{
Edi Karyadi \\ Fakultas Kedokteran Gigi Universitas Muhammadiyah Surakarta \\ Correspondence to: drg. Edi Karyadi \\ Email :edikaryadi@ums.ac.id
}

\begin{abstract}
Until now there is no standard for measuring the standard willingnesss to pay of patients and patient satisfaction for the quality of dental care. Research purposes to assess the magnitude of willingness to pay for outpatient dental care and want to test the factors that affect willingness to pay for outpatient dental care at the Muhammadiyah Medical Center (MMC UMS). This study was observational analytic study with cross-sectional approach, where all the variables studied were observed at the same time. The study population was patients who received outpatient dental care with simple random sampling. To the adequacy of the sample required a minimum sample size of 120. The data collection by questionnaire content validity technique. The results showed $60.8 \%$ of patient education level is college. The average patient's willingness to pay for dental care Rp.60.833. The average satisfaction score of patients on dental health servicesis 77.35 (including the high satisfaction category). While the average patient income for Rp.2.110.417. Statistical analysis proves' there is a positive correlation' between service quality and willingness to pay for dental care patients $(r=0247, p<0.05)$. In this study also proves' there is a positive correlation' between the patient and the willingness to pay in comedental care $(r=0.730, p<0.05)$. With the regression test showed the 'threev ariables (education, income and quality of service)' jointly able to predict variations in the willingness of patients to pay for $59.7 \%$ and statistically fit regression model (valid) $(p<0.001)$.
\end{abstract}

Keywords: education, income, quality of service, willingnestopay

\section{PENDAHULUAN}

Penyakit gigi dan mulut merupakan masalah utama yang diderita oleh $90 \%$ penduduk di Indonesia. Prevalensi penyakit ini cenderung meningkat, dan bila tidak dilakukan perawatan maka akan semakin parah. Penyakit gigi dan mulut yang banyak ditemukan di masyarakat adalah penyakit karies gigi.

Apabila masalah karies dibiarkan dan kecenderungan peningkatannya di masa mendatang tidak dicegah, dampaknya akan sangat merugikan seluruh masyarakat. Akibat penyakit karies antara lain : rasa sakit, gangguan fungsi kunyah yang menghambat konsumsi makanan/nutrisi, gangguan kenyamanan berupa gangguan tidur, gangguan konsentrasi belajar dan produktivitas kerja. hilangnya kesempatan menerjuni bidang karier tertentu misalnya masuk ABRI, penerbang atau pramugari, yang akhirnya mempengaruhi kualitas sumber daya manusia (Perio, 2001).
Penyakit gigi dan mulut yang banyak diderita anak-anak maupun dewasa adalah penyakit pada jaringan keras gigi yaitu karies, yang dipengaruhi oleh konsumsi refined carbohydrate seperti gulagula/biskuit, makanan lunak tidak berserat, yang bersifat kariogenik. Penyakit periodontal juga merupakan salah satu penyakit gigi dan mulut yang banyak ditemukan pada masyarakat Indonesia. Penyebab utama penyakit periodontal adalah plak. Oleh karena itu perlu dilakukan penghilangan plak, melalui peningkatan kesehatan gigi dan mulut pada masyarakat (Tjahja, 2006).

Produktivitas terganggu akibat penyakit gigi memang sudah menjadi fakta yang jelas. Tidak hanya dari sisi medis, ketidakpedulian masyarakat pada penyakit gigi dan mulut secara ekonomis juga merugikan.Tahun 2002 International Dental Journal melansir data bahwa di banyak negara penyakit gigi dan mulut merupakan penyakit keempat yang paling mahal biaya penyembuhannya.Pengobatan penyakit gigi 
berlubang berdasarkan data tersebut membutuhkan biaya hingga 3.513 dolar AS per 1.000 orang anak. Anggaran tersebut melebihi anggaran kesehatan yang diperuntukan bagi anak-anak di negara-negara yang paling rendah pendapatan per kapitanya. (Tjahja, 2006).

Pembiayaan kesehatan adalah masalah besar di bidang kesehatan, terutama sistem pelayanan fee for service. Seringkali harga yang ditetapkan tidak sesuai dengan kemauan membayar (Willingness To Pay, WTP) masyarakat yang akan memanfaatkan pelayanan kesehatan yang ditawarkan (Foerit dan Foreit, 2001). Karena itulah, dalam penentuan harga pelayanan kesehatan sangat penting melihat kemauan membayar masyarakat (Walraven, 1996).

WTP adalah jumlah maksimum dari pendapatan dimana individu mau membayar jasa atau barang yang diusulkan tersedia (Walraven, 1996). WTP memberikan tingkat harga yang realistis, dan lebih banyak dipengaruhi oleh selera dan persepsi konsumen (Walraven, 1996).

Kemauan membayar pada diri seseorang dapat dikaitkan pada kumpulan faktor-faktor sosial demografi, seperti usia, pendidikan, jenis kelamin, dan status kesehatan; serta kumpulan faktor ekonomis seperti masalah moneter (misalnya pembayaran, biaya obat-obatan, dan biaya perjalanan) serta aspek non moneter seperti biaya (waktu) untuk mencari pelayanan.

Saat ini, masyarakat mulai banyak yang menyadari pentingnya kesehatan gigi dan mulut sehingga pemakaian pelayanan kesehatan gigi dan mulut juga menunjukkan tren meningkat. Demikian juga yang terjadi di Muhammadiyah Medical Center (MMC) yang merupakan poliklinik di lingkup Universitas Muhammadiyah Surakarta. MMC memberikan pelayanan kesehatan baik kedokteran gigi, maupun umum kepada dosen, karyawan serta mahasiswa di lingkup UMS serta masyarakat sekitar. Selama ini, untuk dosen, karyawan dan mahasiswa, pada pemeriksaan jam kerja pagi dan siang tidak dikenakan biaya, akan tetapi ditanggungkan kepada pihak Universitas.

Tingginya tingkat kunjungan dosen dan karyawan serta mahasiswa Universitas Muhammadiyah Surakarta ke MMC mengakibatkan tingginya biaya yang harus dikeluarkan oleh UMS. Dari data sekunder pada tahun 2006, kunjungan dosen dan karyawan sepanjang tahun 2006 mencapai 3897, atau lebih dari 3 kali lipat jumlah dosen dan karyawan. Mengingat semakin tingginya angka kunjungan terutama di poliklinik gigi MMC dan terbatasnya sumber dana universitas untuk kesehatan dan kesejahteraan dosen, karyawan, dan mahasiswa, penulis menilai pentingnya dilakukan survey untuk mengetahui kemauan membayar pasien rawat jalan untuk pelayanan kesehatan gigi di MMC sehingga dapat menjadi landasan untuk menerapkan tarif yang rasional dan dapat diterima, dan menganalisis faktor-faktor yang mempengaruhinya.

Tujuan penelitian ini adalah untuk menaksir besarnya kemauan membayar pasien rawat jalan terhadap pelayanan kesehatan gigi di MMC UMS dan menguji hipotesis tentang hubungan antara persepsi pasien tentang kualitas dan kemauan membayar pasien rawat jalan terhadap pelayanan kesehatan gigi di MMC UMS.

\section{METODE}

Penelitian ini adalah penelitian analitik observasional dengan pendekatan cross-sectional, dimana semua variabel yang diteliti diobservasi pada waktu yang sama. Penelitian dilakukan di Muhammadiyah Medical Center Universitas Muhammadiyah Surakarta. Populasi penelitian adalah pasien rawat jalan yang mendapat pelayanan kedokteran gigi di MMC UMS. Pengambilan sampel dilakukan dengan systematic sampling yaitu mencuplik sejumlah subyek penelitian secara systematic dari kelompok populasi. Jumlah sampel penelitian ini adalah 120 pasien.

\section{HASIL DAN PEMBAHASAN}

\section{Deskripsi Lokasi dan Subyek Penelitian}

Pemeriksaan dilakukan terhadap 120 pasien dan kesemuanya dijadikan subyek penelitian. 120 pasien yang terdiri dari 74 laki-laki, dan 46 perempuan yang mana merupakan pasien gigi di MMC-UMS.

Data yang diperoleh dari penelitian dapat disajikan dalam tabel-tabel sebagai berikut:

Tabel 1. Distribusi Subyek Penelitian Berdasarkan Jenis Kelamin

\begin{tabular}{lcc}
\hline \multicolumn{1}{c}{ Jenis Kelamin } & Frekuensi & Prosentase \\
\hline Laki-laki & 74 & $62 \%$ \\
Perempuan & 46 & $38 \%$ \\
Jumlah & 120 & $100 \%$ \\
\hline
\end{tabular}

Sebagian besar subyek (62\%) berjenis kelamin laki-laki dan subjek selebihnya berjenis 
kelamin Perempuan (38\%). Hal ini diperkirakan karena laki-laki adalah sebagai penentu kebijakan dan sebagai pencari nafkah, disamping itu subyek adalah karyawan Universitas Muhammadiyah Surakarta yang mayoritas adalah laki-laki.

Tabel 2 menunjukkan bahwa jumlah sampel pada penelitian ini adalah 120. Rata-rata kemauan membayar pelayanan gigi sebesar Rp. 60.833,nilai terendah kemauan membayar pelayanan gigi adalah sebesar Rp. 20.000,- dan tertinggi sebesar Rp. 125.000,-. Sedangkan kepuasan pasien terhadap pelayanan gigi rata-rata sebesar 77,35 , nilai terendah 66 dan nilai tertinggi 84. Artinya banyak pasien merasa puas terhadap pelayanan kesehatan gigi di MMC-UMS. Adapun ratarata pendapatan pasien sebesar Rp. 2.110.417,-, pendapatan terendah Rp. 1.200.000,- dan tertinggi Rp. 3.500.000,-.

Tabel 2. Deskripsi karakteristik sampel (data kontinu)

\begin{tabular}{lcrrr}
\hline Variabel & $\mathrm{n}$ & Mean & SD & Min \\
\hline Kemauan membayar & 120 & 60,833 & 29,387 & 20,000 \\
Kepuasan & 120 & 7.35 & 3.75 & 66.00 \\
Pendapatan & 120 & $2,110,417$ & 573,611 & 84.00 \\
\hline
\end{tabular}

Tabel 3 menunjukkan bahwa jumlah subyek penelitian 120 . 60,83\% Perguruan Tinggi dan sisanya 39,17\% berpendidikan SLA.

Tabel 3. Deskripsi Karakteristik Sampel (Data Kategorikal)

\begin{tabular}{lcc}
\hline Variabel & $\mathrm{n}$ & Persen \\
\hline Pendidikan & \\
SMA & 47 & 39.17 \\
PT & 73 & 60.83 \\
Total & 120 & 100.00 \\
\hline
\end{tabular}

2. Analisis Hubungan antara Persepsi Pasien Tentang Kualitas Dan Kemauan Membayar Pelayanan Kesehatan Gigi di MMC-UMS

Gambar 1. Menunjukkan diagram sebar (scatter plot) antara kualitas pelayanan dan kemauan membayar pelayanan kesehatan gigi. Gambar tersebut menunjukkan terdapat korelasi positif antara kualitas pelayanan dan kemauan membayar pelayanan kesehatan gigi $(r=0.247$; $<0.01)$.

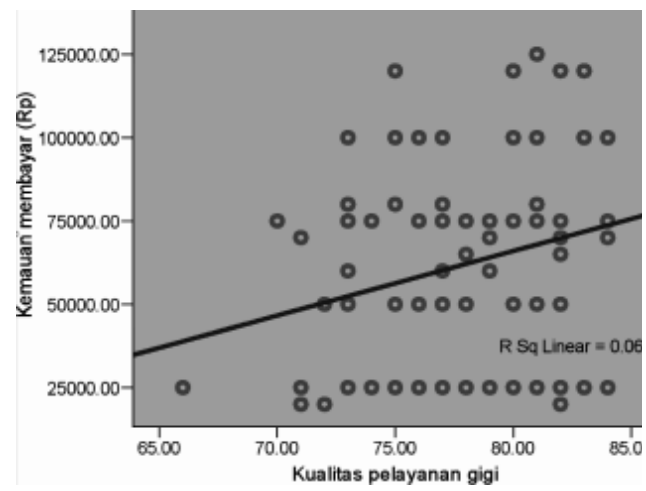

Gambar 1.Hubungan antara persepsi pasien tentang kualitas dan kemauan membayar pelayanan kesehatan gigi

\section{Analisis Hubungan antara Pendapatan Pasien Dan Kemauan Membayar Pelayanan Kesehatan Gigi di MMC - UMS}

Gambar 2. Menunjukkan diagram sebar (scatter plot) antara pendapatan dan kemauan membayar pelayanan kesehatan gigi. Gambar tersebut menunjukkan terdapat korelasi positif antara pendapatan dan kemauan membayar pelayanan kesehatan gigi $(\mathrm{r}=0,730 ; \mathrm{p}<0.01)$.

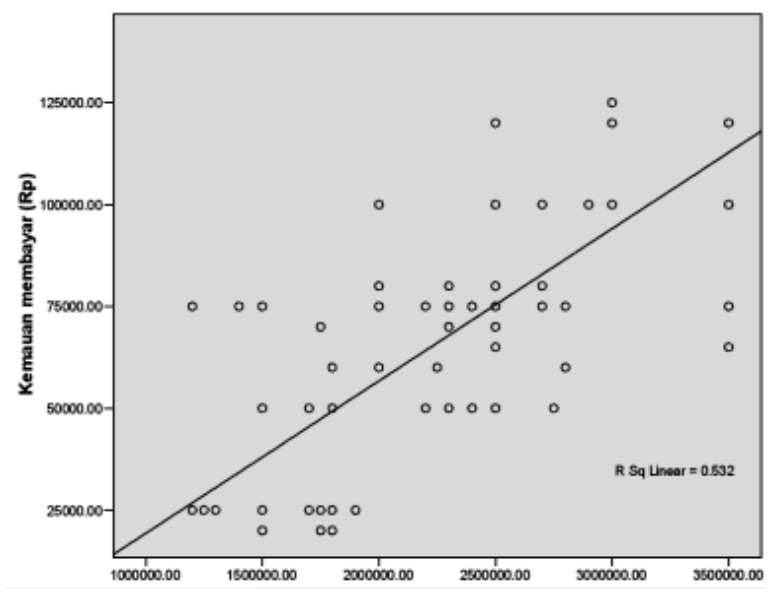

Gambar 2.Hubungan antara pendapatan dan kemauan membayar pelayanan kesehatan gigi 
Tabel 4. Hasil analisis regresi linier ganda tentang hubungan antara persepsi pasien tentang kualitas dan kemauan membayar pelayanan kesehatan gigi

\begin{tabular}{|c|c|c|c|c|}
\hline \multirow{2}{*}{ Variabel } & \multirow{2}{*}{$\beta$} & \multirow{2}{*}{$\mathbf{p}$} & \multicolumn{2}{|c|}{ Confidence Interval } \\
\hline & & & Batas Bawah & Batas Atas \\
\hline Kualitas pelayanan & 1,155 & 0.016 & 217 & 2092 \\
\hline Pendapatan per bulan (Rupiah) & 0.020 & 0.000 & 0.010 & 0.031 \\
\hline \multicolumn{5}{|l|}{ Pendidikan: } \\
\hline SMA & 0 & & & \\
\hline PT & 22,813 & 0.000 & 10,924 & 34,701 \\
\hline \multicolumn{5}{|l|}{$\mathrm{N}$ obsevasi $=120$} \\
\hline \multicolumn{5}{|l|}{ Adjusted $\mathrm{R}^{2}=0.59$} \\
\hline $\mathrm{p}=0.000$ & & & & \\
\hline
\end{tabular}

Dari tabel 4. dapat dilihat nilai $\mathrm{p}$ dan nilai Adjusted R Square dari persamaan regresi linier. Nilai $\mathrm{p}$ menunjukkan signifikansi dari persamaan regresi linier. Persamaan dianggap bermakna secara statistik bila $\mathrm{p}=0,000$. Hal tersebut menunjukkan bahwa variabel-variabel bebas yang digunakan dalam persamaan secara bersama-sama berpengaruh terhadap variabel tergantung (Setiaji, 2006).

Tabel 4. menunjukkan hasil analisis regresi linier ganda tentang hubungan antara persepsi pasien tentang kualitas dan kemauan membayar pelayanan kesehatan gigi. Hasil analisis tersebut menunjukkan bahwa setiap 1 unit (yaitu 1 skor) pertambahan kualitas pelayanan akan diikuti oleh pertambahan kemauan membayar pelayanan kesehatan gigi sebesar Rp 1,155. Dengan kata lain setiap 10 skor pertambahan kualitas pelayanan akan diikuti oleh pertambahan kemauan membayar pelayanan kesehatan gigi sebesar Rp 11,550. Hubungan positif tersebut secara statistik signifikan $(\mathrm{p}=0.016)$.

Selanjutnya, hasil analisis regresi linier tersebut menunjukkan bahwa setiap 1 unit (yaitu $\mathrm{Rp}$ 1) pertambahan pendapatan keluarga per bulan akan diikuti oleh pertambahan kemauan membayar pelayanan kesehatan gigi sebesar Rp 0.020. Dengan kata lain setiap Rp 100,000 pertambahan pendapatan keluarga akan diikuti oleh pertambahan kemauan membayar pelayanan kesehatan gigi sebesar Rp 2,000. Hubungan positif tersebut secara statistik signifikan $(\mathrm{p}=0.000)$.

Demikian pula terdapat hubungan positif antara tingkat pendidikan dan kemauan membayar pelayanan kesehatan gigi. Individu dengan tingkat pendidikan perguruan tinggi, rata-rata memiliki kemauan membayar Rp 22,813 lebih besar daripada individu dengan tingkat pendidikan SLA. Hubungan secara statistik signfikan $(p=0.000)$.

Ketiga variabel tersebut, yakni, persepsi pasien tentang kualitas, pendapatan keluarga, dan pendidikan, secara bersama-sama mampu menjelaskan/ memprediksi variasi dalam kemauan membayar sebesar 59\%, dan secara statistik signifikan $(\mathrm{p}=0.000)$.

Tabel 5. Koefisien regresi dari seluruh variabel bebas

\begin{tabular}{llll}
\hline \multicolumn{1}{c}{ Variabel yang dianalisis } & \multicolumn{1}{c}{$\mathrm{b}$} & \multicolumn{1}{c}{$P$} & Keputusan \\
\hline Pendidikan & 22812,5 & 0,001 & \\
Pendapatan & 0,02 & 0,001 & \\
Persepsi tentang kualitas & 1154,78 & 0,016 & \\
(Konstanta) & -108103 & 0,003 & \\
\hline
\end{tabular}

Pengujian regresi dengan mencari koefisien model regresi seperti pada tabel 5. diatas bertujuan untuk mengetahui 'variabel mana yang paling berpengaruh' terhadap kemauan pasien membayar playanan kesehatan gigi (WTP). Ketentuan yang dipergunakan adalah dengan melihat nilai $p$ yang terkecil dari seluruh nilai $p$ hasil analisis regresi. Pada tabel diatas diketahui nilai $\mathrm{p}$ terkecil adalah 0,001 yaitu variabel pendidikan dan pendapatan pasien.Artinya, variabel pendidikan pasien dan pendapatan pasien adalah variabel yang paling berpengaruh. Adapun pendidikan, pendapatan, dan persepsi tentang kualitas pelayanan kesehatan gigi adalah variabel 'determinant' (yang mempengaruhi) kemauan membayar pelayanan kesehatan gigi (WTP).

Selanjutnya pada tahap akhir uji regresi berganda adalah membuat model d engan formulasi matematik, seperti ditunjukkan dibawah.

$$
\mathrm{Y}=\mathrm{a}+(\mathrm{bX} 1)+(\mathrm{cX} 2)+(\mathrm{dX} 3)
$$

Kemauan membayar $(\mathrm{WTP})=-108103+\mathrm{b}(22812,5)+\mathrm{d}(1154,78)$ 


\section{SIMPULAN}

Dari hasil analisis data, dapat diambil kesimpulan tentang faktor-faktor yang mempengaruhi Kemauan Membayar (Willingness to Pay) pelayanan kesehatan gigi di MMC-UMS. Data yang diambil berdasarkan pada kuisioner yang diberikan pada pasien yang datang berobat gigi di MMC-UMS dalam rentang waktu penelitian dari bulan Maret sampai dengan bulan Juni 2008. berikut:

Penelitian ini menarik kesimpulan sebagai

1. Terdapat hubungan positif yang secara statistik signifikan antara kemauan membayar pelayanan kesehatan gigi dan persepsi pasien tentang kualitas. Setiap 10 skor peningkatan kualitas akan meningkatkan kemauan membayar sebesar Rp. 11.550,- $\quad(\beta=1.155$, $\mathrm{p}=0.016$ )

2. Validitas perkiraan kemauan membayar pelayanan kesehatan gigi pada penelitian ini ditunjukkan oleh adanya korelasi positif yang secara statistik signifikan diterima Kemauan membayar dan pendapatan subyek penelitian $(\mathrm{r}=0.730, \mathrm{p}=0.000)$

\section{Saran}

Saran pada hasil penelitian ini adalah:

1. Variabel independen yang digunakan untuk menguji hanya 3 variabel yaitu Kepuasan, Pendapatan, dan Tingkat Pendidikan sehingga disarankan untuk menguji lebih banyak lagi faktor fundamental yang mempengaruhi Kemauan Membayar (Willingness to Pay).

2. Data yang digunakan dalam penelitian ini adalah data primer sehingga dalam pengisian kuisioner dimungkinkan jawabannya tidak sesuai dengan yang dikehendaki oleh peneliti.

\section{DAFTAR PUSTAKA}

Binam JN, Nikama A, Nkendah R. 2002. "Estimating the Willingness to Pay for Community Health Prepayment Schemes in Rural Area: A Case Study of the use of Contingent Valuation Survey in Centre Cameroon".

Foreit K.G, Foreit J.R. 2001. "Willingness to Pay Surveys for Setting Prices for Reproductive Health Products and Services". www.blackwellsynergy.com
Hizrani M, et al, 2003. "Analisis Kepuasan Pasien Rawat Inap Terhadap Mutu Pelayanan dan Hubungannya Dengan Minat Beli Ulang di RS X di Jakarta Tahun 2002". Jakarta: Jurnal Managemen dan Administrasi Rumah Sakit Indonesia, Nomor 1 Volume IV, 2003

Murti B. 2005. "Pendapatan, Pendidikan, Tempat Tinggal, dan kemauan Membayar Asuransi Kesehatan Anak: penggunaan Teknik Bidding Game”. JMPK Vol 08/ No $02 / J u n i / 2005$.

Perio I.S. 2007.“Pengembangan Standarisasi Hasil Pemeriksaan Kesehatan Gigi dan Mulut oleh Dokter, Dokter Gigi, serta Perawat Gigi di Tangerang".www. depkes.go.id

Prosser LA, Ray T, O’Brien M, Kleinman K, Santoli J, Lieu TA. 2004. "Preferences and Willingness to Pay for Health States Prevented by Pneumococcal Conjugate Vaccine". Pedicatrics: Official Journal of The American Academy of Pediatrics. www.pediatrics.org/cgi/content/ full/113/2/283

Tjahja I.N, Made Ayu Lely S. 2006. "Hubungan Kebersihan Gigi dan Mulut dengan Pengetahuan dan Sikap Responden di Beberapa Puskesmas di Propinsi Jawa Barat".www.depkes.go.id

Tjahja I.N, Sintawati F.X, Novita T.A. 2007. "Gambaran Karies Gigi permanen di Beberapa Puskesmas Kota dan Kabupaten Bandung, Sukabumi Serta Bogor tahun 2002". www.depkes.go.id

Unutzer J, Katon WJ, Russo J, Simon G, Von Korff M, Lin E, Walker E, Ludman E, Bush T.2003. "Willingness to Pay for Depresion Treatment in Primary Care". www.psychiatryonline.org

Walraven, G. 1996. "Willingness to Pay for Distric Hospital Services in Rural Tanzania". Health Policy and Planning: 11(4): Page 428-437

Setiaji, Bambang, 2006. Panduan Riset Dengan Pendekatan Kuantitatif, Cetakan Pertama. Muhammadiyah University Press, UMS. 